\title{
SELECTION OF FILAMENTOUS FUNGI OF THE BEAUVERIA GENUS ABLE TO METABOLIZE QUERCETIN LIKE MAMMALIAN CELLS
}

\author{
Eula Maria de M. B. Costa ${ }^{1}$; Fabiana Cristina Pimenta ${ }^{2}$; Wolf Christian Luz ${ }^{2}$, Valéria de Oliveira ${ }^{1 *}$ \\ ${ }^{1}$ Laboratório de Bioconversão, Faculdade de Farmácia, Universidade Federal de Goiás, Goiânia, GO, Brasil; ${ }^{2}$ Laboratório de \\ Bacteriologia, Instituto de Patologia Tropical e Saúde Pública, Universidade Federal de Goiás, Goiânia, GO, Brasil.
}

Submitted: June 04, 2007; Returned to authors for corrections: November 02, 2007; Approved: February 21, 2008.

\begin{abstract}
Microbial biotransformations constitute an important alternative as models for drug metabolism study in mammalians and have been used for the industrial synthesis of chemicals with pharmaceutical purposes. Several microorganisms with unique biotransformation ability have been found by intensive screening and put in commercial applications. Ten isolates of Beauveria sp genus filamentous fungi, isolated from soil in the central Brazil, and Beauveria bassiana ATCC 7159 were evaluated for their capability of quercetin biotransformation. Biotransformation processes were carried out for 24 up to 96 hours and monitored by mass spectrometry analyses of the culture broth. All strains were able to metabolize quercetin, forming mammalian metabolites. The results were different from those presented by other microorganisms previously utilized, attrackting attention because of the great diversity of reactions. Methylated, sulphated, monoglucuronidated, and glucuronidated conjugated metabolites were simultaneously detected.
\end{abstract}

Key-words: Beauveria bassiana, Biotransformation, Quercetin.

\section{INTRODUCTION}

Beauveria sp belong to the Moniliaceae family and Beauveria bassiana is the most common species. This species is an entomophatogenic fungus that performs many complex conversions (15) and investigations underlined its potential use as a biological control agent for insect pests, as an alternative to harmful chemical insecticides (14).

B. bassiana ATCC 7159 has been used as a model for different substrates biotransformation. Biochemical evidences showed that the reactions are often mediated by cytochrome P450 and phase II metabolism enzymes $(3,5,12)$.

The biotransformation process using the microorganism whole cell has attracted more attention for the production of pharmaceutical derivatives. One of the advantages to use the intact cell is the reduced cost. Therefore it is not necessary to isolate, purify and stabilize the enzyme (9). The derivatives preparation with high stereo and regio-selectivity under environmental conditions constitute an alternative to chemical reagents (7). The microorganism whole cells also could be employed for bioremediation, biomonitoring, or in the targeted biosynthesis of fine chemicals that are otherwise difficult to manufacture via conventional chemical means that involve complicated procedures (7). An important example of this versatile process for manufacturing a complex pharmaceutical ingredient is the synthesis of statins, which are cholesterollowering drugs (13).

The approval of a substance for human use depends on the evaluation of its metabolism. In some cases the drug metabolism results in metabolites with raised pharmacological activity and potential toxicity. Metabolic studies are carried out in animal models, perfused organs or cellular cultures (1). The microbial biotransformation constitute an important alternative, because mimics the mammalian metabolism. Moreover, the high potential of microbial reactions can be used for the creation of molecular diversity (1). These methodologies have the advantage of a

*Corresponding Author. Mailing address: Laboratório de Bioconversão, Faculdade de Farmácia - Universidade Federal de Goiás, $1^{\mathrm{a}}$ Avenida esquina com Praça Universitária, S/N. Caixa Postal 131, Setor Universitário - CEP: 74.605-220. Goiânia - GO, Brasil. Tel.: (+5562) 3209-6044 R- 221. Fax: (+5562) 3209-6037. E-mail: valeria@farmacia.ufg.br 
reduced animals demand, and permit to obtain higher concentrations of metabolites that facilitate structural identification and toxicological and pharmacological studies, without chemical synthesis (1).

Microbial biotransformations that mimic mammalian metabolism are well understood $(8,15)$, and they include oxidation, reduction (similar to hepatic phase I in animal metabolism) or conjugation (phase II in animal metabolism) reactions. Beauveria bassiana constitute a reliable and efficient alternative to the use of animals or synthetic chemistry and are frequently used in microbial conversion processes (1).

Flavonoids are polyphenolic metabolites of plants and have been proposed to exert a wide range of beneficial effects in human health, preventing chronic and degenerative diseases such as cardiovascular, cerebrovascular, Parkinson's and Alzheimer's diseases (5). Evidences suggest that flavonoids exercise cellular effects, many of which are linked to their interactions with specific proteins pathways $(16,17)$. Quercetin, a flavonoid compound, inhibits protein kinases, DNA topoisomerase, regulates gene expression and has been involved in the transcriptional activation of cytochrome P450 enzymes (5). It is possible that cells exposed to quercetin have higher levels of phase I detoxification enzymes (5). Low concentrations of quercetin could lead to expression of survival and defensive genes, including those related to phase II detoxifying enzymes, such as UDP-glucuronosyltransferase (17).

In this study, ten strains of Beauveria sp and Beauveria bassiana ATCC 7159 were explored for their biotransformation potential, specially for their capability to produce metabolites similar to those produced by mammalian cells or new compounds with interesting biological activities.

\section{MATERIALS AND METHODS}

\section{Chemicals}

Quercetin was purchased from Sigma Chemical Company, St. Louis, MO (USA).

\section{Microorganisms}

Beauveria sp strains (IP3a, IP6, IP8, IP11, IP94, IP98, IP129, IP132, IP147 and IP153) were isolated from soil samples of central Brazil and belong to the fungal culture collection of the Instituto de Patologia Tropical e Saúde Pública of the Universidade Federal de Goiás. All strains were cultured in potato agar.

\section{Culture and biotransformation}

Aliquots of $0.5 \mathrm{~mL}$ of each Beauveria sp and Beauveria bassiana ATCC 7159 conidia suspensions, prepared after seven days of culture, were transferred to Erlenmyer flasks with 100 $\mathrm{mL}$ of liquid peptone dextrose soybean meal - PDSM (peptone $5 \mathrm{~g}$, dextrose $20 \mathrm{~g}$, soybean meal $5 \mathrm{~g}$, dihydrogen potassium phosphate $5 \mathrm{~g}$, sodium chloride $5 \mathrm{~g}$, yeast extract $3 \mathrm{~g}$ in $1 \mathrm{~L}$ of distilled water). The flasks were maintained in shaker under 200 rpm at $29 \pm 2^{\circ} \mathrm{C}$ for 72 hours. Substrate was added to the cultures at a final concentration of $0.5 \mathrm{~g} / \mathrm{L}$ and incubated in the same conditions. Aliquots $(1.0 \mathrm{~mL})$ of the supernatant were taken every 24 hours, up to $96 \mathrm{~h}$. The samples were saturated with sodium chloride, extracted with ethyl acetate, and centrifuged at $3000 \mathrm{xg}$ for $10 \mathrm{~min}$. The organic phases were dried on $\mathrm{MgSO}_{4}$, evaporated and then added to $500 \mu \mathrm{L}$ of HPLC-grade methanol before injection into ESI/MS.

\section{Chromatographic procedures}

Analytical reverse-phase HPLC was carried out using Gilson pumps, a Gilson 321 sample injector equipped with a $20 \mu 1$ loop and a UV detector. A Lichospher $100 \mathrm{RP} 18$ colunm $(0.5 \mu, 250$ $\mathrm{mm} \times 4.6 \mathrm{~mm}$ ) was used. The analyses were carried out at room temperature. Detection was set at $254 \mathrm{~nm}$. The flow rate was 1.0 $\mathrm{ml} / \mathrm{min}$. A gradient elution of methanol-water (65:35) was used over 9 min. Calibration was performed using previously prepared standard solutions of quercetin and their metabolites, purified and characterized by ${ }^{1} \mathrm{H}$ and ${ }^{13} \mathrm{C}$ NMR and LC-MS (data not shown).

\section{ESI-MS analysis}

This analysis was carried out in an Atmospheric Pressure Ionization 1200L quadrupole MS/MS instrument (VARIAN, inc.) at $400^{\circ} \mathrm{C}$, nebulizer pressure $23-24$ psi, capillary voltage $40 \mathrm{~V}$, needle $5000 \mathrm{~V}$, and shield $600 \mathrm{~V}$, using the previously described reverse-phase chromatographic method, substituting the gradient system with water by methanol in isocratic conditions at flow rate $0.5 \mathrm{~mL} / \mathrm{min}$. The flow rate of the electrospray solutions to the ion source was $5 \mu \mathrm{L} / \mathrm{min}$. and nitrogen was used as collision gas. The analyses were carried out in the positive ionization mode and were recorded in scan mode in the mass range from 250 to 1000 Th. A VARIAN ${ }^{\circledR}$ Workstation system software was used for data acquisition and processing.

\section{RESULTS AND DISCUSSION}

The molecular ions of relevant quercetin metabolites, showed in Beauveria sp biotransformation were: $m / z$ (315-316), $m / z$ (380383 ), $m / z$ (477-479 and $m / z$ (491-492). These ions corresponded to the metabolites 2, 3, 4 and 5 (Fig. 1) reported in previous studies on quercetin metabolism by various biological systems $(10,11,18)$.

ESI- MS spectrum revealed that quercetin was extensively metabolized by fungal enzymes and irrelevant differences were observed in the distribution of quercetin derivatives after substrate contact. The time courses of metabolites accumulation were similar and the biotransformation produced conjugated metabolites. In general, the conjugates formed the molecular ion $(\mathrm{m} / \mathrm{z} 383)$ suggesting quercetin sulphatation, $\mathrm{m} / \mathrm{z}(479)$ monoglucuronidation and $\mathrm{m} / \mathrm{z}$ (492) monoglucuronidation and sulphatation. The molecular ions $(\mathrm{m} / \mathrm{z} 315)$ and $(\mathrm{m} / \mathrm{z} 303$ 


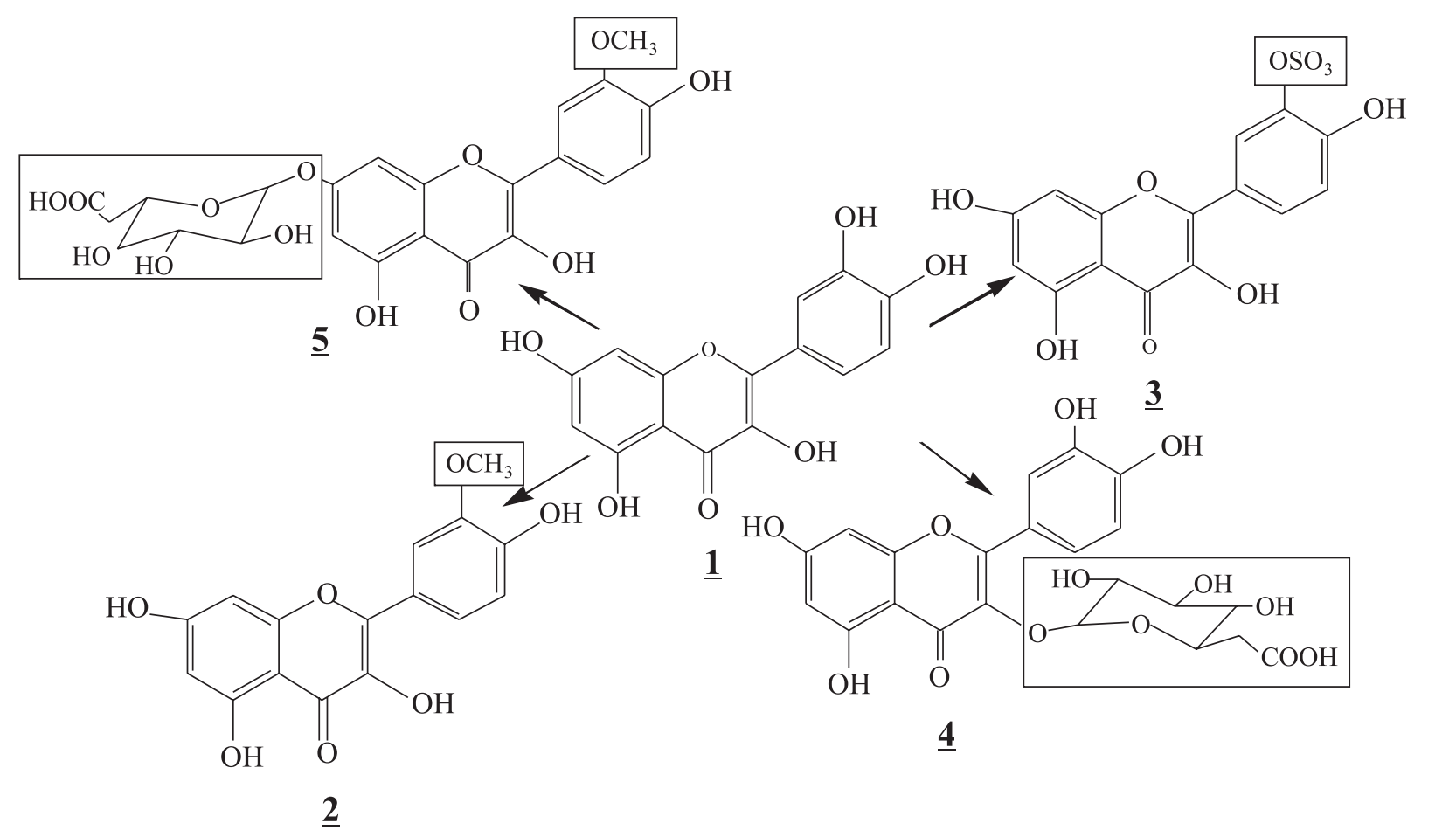

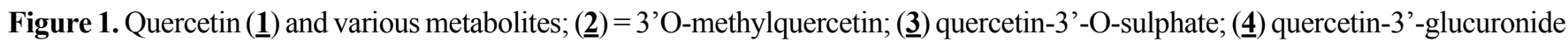
and $(\underline{\mathbf{5}})=3^{\prime} \mathrm{O}$-methylquercetin-7-glucuronide $(10,11,18)$.

$\left.\left[\mathrm{MP}^{+} 1\right]\right)$ corresponded to a methylation and quercetin aglycone, respectively. Table 1 shows the metabolites detected in the supernatant after incubation of each isolate for 72 hours. Five strains (IP 94, IP 98, IP 129, IP 147 and B. bassiana ATCC 7159) produced methylation, three isolates (IP 8, IP 11 and IP 94) produced monoglucuronidation and all strains produced sulphatation and methylation and monoglucuronidation simultaneously. The strain IP 94 produced all reactions types.

Species of Bacillus, Aspergillus, Streptomyces and Penicillium transformed quercetin into numerous metabolites by hydroxylation, glucosylation and methylation (2). Only Streptomyces griseus appear to mimic mammalian metabolism, mediating methylation of quercetin. The other fungi simulate metabolic patterns observed in plants (2).

Comparing the ESI-MS profiles to previous studies on the enzymatic derivatization of flavonoids, it was possible to confirm that reactions occurred on the aglycone structure. The hydroxil groups of quercetin were targets for conjugation reactions such as glucuronidation, sulphation and methylation. As reported by different authors, conjugations are the most common final step reactions in mammalian metabolism of intact flavonoids. After absorbed and metabolized in the intestine, they are further metabolized in the liver to yield various conjugated forms $(6,10$, $11,18)$. Several flavonoids such as quercetin, naringin, and genistein are observed commonly in mammal's urine or bile as glucuronide or sulfate conjugates or methyl ethers (2).

The molecular ions observed in the ESI-MS results are in consonance with LC-MS analysis and H Nuclear Magnetic Ressonance (HNMR) data reported by Oliveira \& Watson (11) and O'Leary et al. (10). Woude et al (18) also detected 14 different phase II mono and mixed conjugates of quercetin in various biological systems such as rat liver microsomes, human hepatic microsomes, rat small intestine, human small intestine, rat plasma and human plasma. These authors concluded that the plasma phase II metabolic pattern in mammalians is a result of interplay of different organs with metabolizing capacity, specially the liver and the small intestine. The same pattern was observed by Herath et al. (6) in experiments with Beauveria bassiana ATCC 7159, for 3- and 7-hydroxyflavones.

Glucuronidation, sulphatation and methylation were the most common metabolic pathways in quercetin biotransformation, indicating that the screened fungi express phase II metabolic enzymes when exposed to these xenobiotics.

The investigation leads to the conclusion that the tested filamentous fungi presented phase II biotransformation patterns. They offer significant potential for use in microbial models to mimic mammalian metabolism and represent powerful biotechnological research tools for biotransformation of 
Table 1. Biotransformation of quercetin by strains of Beauveria sp and Beauveria bassiana ATCC 7159.

\begin{tabular}{lcccc}
\hline \multirow{2}{*}{ Strains } & \multicolumn{5}{c}{ Metabolites } \\
\cline { 2 - 5 } & $\mathbf{( 2 )}$ & $\mathbf{( 3 )}$ & $\mathbf{( 4 )}$ & $\mathbf{( 5 )}$ \\
& $(315-316)$ & $m / z$ & $m / z$ & $m / z$ \\
$(380-383)$ & $(477-479)$ & $(491-492)$ \\
\hline Beauveria bassiana & + & + & - & + \\
ATCC 7159 & & & & \\
IP 3a & - & + & - & + \\
IP 6 & - & + & - & + \\
IP 8 & - & + & + & + \\
IP11 & - & + & + & + \\
IP 94 & + & + & + & + \\
IP 98 & + & + & - & + \\
IP 129 & + & + & - & + \\
IP 132 & - & + & - & + \\
IP 147 & + & + & - & + \\
IP 153 & - & + & - & + \\
\hline
\end{tabular}

$(+)$ presence, (-) absence; Metabolites pattern fragmentation detected by ESI-MS in the supernatant at 72 hours after incubation. Analysis conditions: mobile phase, methanol, drying gas temperature $400^{\circ} \mathrm{C}$, flow rate $0.5 \mathrm{~mL} / \mathrm{min}$, nebulizer pressure 23-24 psi, capillary voltage $40 \mathrm{~V}$, needle $5000 \mathrm{~V}$, and shield $600 \mathrm{~V}$. The flow rate of the electrospray solutions to the ion source was $5 \mu \mathrm{L} / \mathrm{min}$.

quercetin, specially the strain IP 94, that presented the largest reaction diversity.

\section{RESUMO}

\section{Seleção de fungos filamentosos do gênero Beauveria capazes de metabolizar quercetina de forma semelhante aos mamíferos}

Biotransformações microbianas constituem uma alternativa importante como modelo para o estudo do metabolismo de medicamentos em mamíferos e são empregadas em processos sintéticos industriais com propósitos farmacêuticos. Diversos microrganismos com potencial para biotransformação têm sido encontrados através de screening intensivo e aplicados comercialmente. Dez cepas de fungos filamentosos do gênero Beauveria, isolados na região central do Brasil, e a cepa Beauveria bassiana ATCC 7159 foram avaliadas quanto à capacidade de biotransformação da quercetina. As reações de biotransformações foram realizadas por um período de 24 a 96 horas, e monitoradas através de espectrometria de massas do meio reacional. Todas as cepas foram capazes de metabolizar a quercetina, formando metabólitos encontrados nos mamíferos. Os resultados foram diferentes dos resultados apresentados por outros microrganismos utilizados anteriormente e chamam a atenção devido à diversidade das reações evidenciadas. Diferentes metabólitos conjugados foram detectados simultaneamente: metilados, sulfatados, monoglicuronados, e glicuronados.

Palavras-chave: Beauveria bassiana, Biotransformação, Quercetina.

\section{REFERENCES}

1. Azerad, R. (1999). Microbial Models for Drug Metabolism. Adv. Biochem. Eng. Biotechnol., 63, 163-218.

2. Das S.; Rosazza, J.P.N. (2006). Microbial and Enzimatic Transformations of Flavonoids. J. Nat. Prod., 69, 499-508.

3. Grogan, G.J.; Holland, H.L. (2000). The biocatalytic reactions of Beauveria spp. J. Mol. Catal., B Enzym., 9, 1-32.

4. Haufe, G.; Wölker, D.; Fröhlich, R. (2002). Selectivity of biohydroxylation with Beauveria bassiana of trans-2-fluorocycloalkyl N-phenylcarbamates. J. Org. Chem., 67 (9), 3022-3028.

5. Havsteen, B.H. (2002). The biochemistry and medical significance of the flavonoids. Pharmacol. Ther., 96, 67-202.

6. Herath, W.; Mikell, J.R.; Hale, A.L.; Ferreira, D.; Khan, I.A. (2006). Microbial Metabolism of metabolites of 3- and 7-Hydroxyflavones. Chem. Pharm. Bull, 54 (3), 320-324.

7. Keppler, A.F.; Porto, A.L.M.; Schoenlein-Crusius, I.H.; Comasseto, J.V.; Andrade, L.H. (2005). Enzymatic evaluation of different Aspergillus strains by biotransformation of cyclic ketones. Enzyme Microb. Technol., 36, 967-975.

8. Ma Xiao-chi; Ye Min; Wu Li-jun; Guo De-an. (2006). Microbial transformation of curdione by Mucor spinosus. Enzyme Microb. Technol., 38, 367-371.

9. Mulinacci, N.; la Marca, G.; Innocenti, M.; Vincieri, F.F.; CrespiPerellino, N.; Minghetti, A. (2005). Cell cultures of Ajuga reptans L. to bioconvert emodin and aloe-emodin: an HPLC/ESI/MS investigation. Enzyme Microb. Technol., 36, 399-408.

10. O'Leary, K.A.; Day, A.J.; Needs, P.W.; Mellon, F.A.; O’Brien, N.M.; Williamson, G. (2003). Metabolism of quercetin-7- and quercetin-3glicuronides by an in vitro hepatic model: the role of human bglucuronidase, sulfotransferase, catechol- $O$-methyltransferase and multi-resistant protein 2 (MRP2) in flavonoid metabolism. Biochem. Pharmacol., 65, 479-491.

11. Oliveira, E.J.; Watson, D.G. (2000). In vitro glucuronidation of kaempferol and quercetin by human UGT-1A9 microsomes. FEBS Lett., 471, 1-6.

12. Olivo, H.F.; Peeples, T.L.; Rios, M.Y.; Velazquez, F.; Kim, J.W.; Narang, S. (2003). Microbial C-hydroxilation and $\beta-4-O-$ methylglucosidation of methylbenzamide 7-azanorbomane ethers with Beauveria bassiana. J. Mol. Catal., B Enzym., 21, 97-105.

13. Panke S.; Wubbots M. (2005). Advances in biocatalytic synthesis of pharmaceutical intermediates. Curr. Opin. Chem. Biol., 9, 188-198.

14. Purwar, J.R.; Sachan, G.C. (2006). Insect pest through entomogenous fungi: A rewiew. J. Appl. Bioscience, 32 (1), 1-26.

15. Van den Brink, H.J.M.; van Gorcom, R.F.M.; van den Hondel, C.A.M.J.J.; Punt, P.J. (1998). Cytochrome P450 Enzyme Systems in Fungi. Fungal Genet. Biol., 23, 1-17.

16. Walle, T. (2004). Absorption and metabolism of flavonoid. Free Radic. Biol. Med., 36, 829-837.

17. Williams, R.J.; Spencer, J.P.E.; Rice-Evans, C. (2004). Flavonoids antioxidants or signaling molecules? Free Radic. Biol. Med., 36, 838-849.

18. Woude, H. van der; Boersma, M.G.; Vervoot, J.; Rietjens, I.M.C.M. (2004). Identification of 14 Quercetin Phase II Mono and Mixed Conjugates and Their Formation by Rat and Human Phase II in Vitro Model Systems. Chem. Res. Toxicol., 17, 1520-1530. 